\title{
O Papel do Docente na Articulação entre as Tecnologias de Informação e Comunicação e a Aprendizagem do Aluno
}

\author{
Priscila Araujo Evangelista ${ }^{1^{*}}$; Luiz Leite de Menezes² \\ ${ }^{1}$ Universidade Federal de São Paulo \\ 2Universidade de São Paulo \\ * Autora para correspondência: pri_ae@hotmail.com
}

\section{RESUMO}

Considerando a crescente utilização e os avanços no campo da Tecnologia de Informação e Comunicação (TIC) no nosso cotidiano, este trabalho tem como objetivo identificar como o docente pode valer-se das teorias de aprendizagem e das TIC para o melhor rendimento de seus alunos. Trata-se de uma pesquisa de natureza qualitativa e com caráter de revisão bibliográfica de literatura, exclusivamente de artigos publicados de 2000 até 2014, nas línguas portuguesa, inglesa e espanhola. Foram encontrados sete artigos na base de dados Scientific Electronic Library On-line (SciELO) e, dentre esses, selecionados cinco para compor a análise. A conclusão dessa revisão é que a inserção de novas metodologias, que utilizem as TICs, é possível e extremamente positiva para o aluno em seu processo de aprendizagem; no entanto, esse será um grande desafio ao docente, uma vez que o modelo vivenciado ainda tem muito da escola tradicional.

Palavras-Chave: Educação; Aprendizagem e Projetos de Tecnologias de Informação e Comunicação.

\begin{abstract}
With the growing utilization and advances at the Informatics and Communication Technology (TIC) field in our days, this article has as a goal to identify how the teacher can use the learning theories and TIC for better results from the students. It's a qualitative research and character of literature review, only for articles published between 2000 and 2014, in portuguese, english and spanish language. Seven articles have been found in database Scientific Electronic Library Online (SciELO), after selection, five have been chosen to compose de analysis. The conclusion was that the insertion of the new methodologies, that use the TIC is possible and very positive for the students in their learning process, however, it will be a huge challenge for the teachers, since the experienced model still has a lot of the traditional school.
\end{abstract}

Keywords: Education; Learning and Informatics and Communication Technology Projects.

\section{Introdução}

As Tecnologias de Informação e Comunicação (TICs) estão evoluindo e ganhando cada vez mais espaço em nossa sociedade, seja para fim recreativo ou para trabalho. Fato é que as TICs estão interferindo nas nossas relações interpessoais, o que inclui mudanças na relação entre aluno e professor (ROSSETTI \& MORALES, 2007).

A concepção tradicional de ensino, que ainda é vista nos dias de hoje, traz o aluno como um coadjuvante, passivo em seu processo de aprendizado, cabendo ao professor ser a parte ativa, o detentor dos conhecimentos que se depositarão no aluno.
Essa é a denominada metodologia expositiva (VASCONCELOS, 1992). Hoje, há uma tendência de desconstruir as visões que colocam os alunos na condição de "depósitos" de conhecimento e o professor como "depositador". Ao contrário, ao professor cabe a função de articulador do conhecimento, que se origina a partir dele, dos alunos e do contexto do qual fazem parte.

A metodologia dialética propõe que o professor argumente e articule no coletivo o conteúdo, levando o argumento a ser trabalhado, pensado e reelaborado pelos alunos. Esse modelo metodológico dialoga intimamente com a aprendizagem 
significativa, uma vez que a dialética se preocupa em mobilizar para o conhecimento, construí-lo e elaborar sua síntese, considerando o significado que ele traz para o aluno (AUSUBEL, 1982).

Se estamos falando de articular o conhecimento, e atualmente as informações de todos os tipos sobre os mais variados assuntos estão a um clique no computador, é possível que o professor se inteire de algumas ferramentas tecnológicas a fim de permitir uma troca mais rica dentro da aula.

"Há ferramentas que estão disponíveis e há educadores que podem usar essas ferramentas de um modo ou de outro" (AVANCINI, CONTE \& GOUVEIA, 2011). Para além da disponibilidade em conhecer novas ferramentas, o professor encontra ainda um trabalho bastante árduo para adaptar a ferramenta a seu conteúdo e turma, uma vez que há poucas chances de padronização, já que o contexto e significados não serão sempre os mesmos.

O professor deve ver essa interação e o desafio de integrar conhecimento e vivência dos alunos com as possibilidades que as tecnologias nos proporcionam, como forma de aproximar os alunos da escola e melhorar o rendimento em aula, conhecendo as ferramentas e trazendo-as à realidade em sala (CAVALCANTI, 1999).

Nesse particular, o processo de aprendizagem exige que haja um clima de trabalho para que o aluno possa sentir satisfação pelo conhecimento adquirido. $\mathrm{O}$ ato de aprender deve possibilitar condições para que o aluno pense e elabore as relações entre os conteúdos, a partir de ações e níveis de responsabilidades próprias e específicas, algo perfeitamente alcançável com o uso de TICs (ANASTASIOU \& PESSATE, 2007).

A inserção da informática na educação brasileira ocorreu de maneira mais efetiva no início da década de 1990. Nessa época, houve o desenvolvimento de pesquisas a fim de usar o computador como um recurso pedagógico, as atividades das pesquisas objetivavam a utilização de computadores na aprendizagem. Além do incentivo à pesquisa, o Ministério da Educação (MEG) promoveu a capacitação de docentes das mais diversas áreas para que se apro- priassem da informática e se servissem dela como recurso em suas aulas (ALMEIDA, 2000).

Em 1997, o MEG criou o denominado Programa Nacional de Informática na Educação - ProInfo, cujo objetivo era a incorporação da tecnologia como ferramenta adicional à prática pedagógica de diferentes áreas de conhecimento, favorecendo a aprendizagem do aluno no ensino público fundamental e médio, com ênfase em projetos de trabalho. A partir de 2007, o ProInfo se tornou o Programa Nacional de Tecnologia Educacional, a fim de utilizar as TICs com mais ênfase e maior abrangência na rede pública de ensino (BRASIL, 2012).

Teorias como a da Aprendizagem Significativa e a prática do Professor Reflexivo possibilitavam que os professores se posicionassem ao lado do aluno, permitindo-lhes compreender as dificuldades dele, auxiliando na superação destas dentro do processo de aprendizagem, além de lançarem desafios encorajando a superação dos limites pelos alunos.

A Teoria da Aprendizagem Significativa implica trazer à realidade do aluno o conceito novo que se aprende, facilitando o acesso ao conhecimento, e, para além disso, desenvolver sua capacidade de reflexão; isto é, implica reavaliar os métodos que se usam em sala de aula, a fim de permitir o máximo de aproveitamento do conteúdo, despertando a curiosidade para que o aluno se aprofunde fora da sala de aula também (AUSUBEL, 1982).

A prática do Professor Reflexivo consiste na atuação junto ao aluno, de modo a sempre refletir a respeito do que foi feito, analisando a situação que foi vivenciada na sala de aula, com o objetivo de avaliar a ação e modificar o que for necessário para melhorar as abordagens futuras, sendo os alunos convidados a construírem essa reflexão junto ao professor (ALARCÃO, 2005). As duas teorias de educação, minimamente apresentadas neste trabalho, podem permitir ao docente a inserção de novas tecnologias na prática pedagógica.

\section{Objetivos}

\section{Objetivo geral}

Com a elaboração do presente trabalho acadêmico, tem-se como prioridade identificar a forma 
como o docente pode se valer das teorias de aprendizagem e das Tecnologias de Informação e Comunicação para o melhor rendimento de seus alunos.

\section{Objetivos específicos:}

- Possibilitar que os professores se apropriem das Tecnologias de Informação e Comunicação, tornando-as facilitadoras de seu trabalho em conjunto com os alunos.

- Identificar as teorias de aprendizagem que permitem a flexibilização do papel do docente enquanto articulador de conhecimento, propiciando a incorporação de novas tecnologias em suas práticas.

\section{Metodologia de Pesquisa}

Trata-se de uma pesquisa de natureza qualitativa e com caráter de revisão bibliográfica de literatura. Para responder à indagação motivadora do trabalho, será necessária grande revisão bibliográfica, a fim de encontrar material referente às possibilidades para que o professor seja um articulador entre o processo de aprendizagem do aluno e as Tecnologias de Informação e Comunicação.

O estudo será descritivo, uma vez que haverá a caracterização de cada uma das estratégias encontradas, com o propósito de se analisarem suas potencialidades, assim como suas fragilidades, para que esta seja uma ferramenta segura aos profissionais da educação.

Constituíram critérios de inclusão na pesquisa: tratar-se de artigos completos, redigidos nas línguas portuguesa, espanhola e inglesa, e publicados desde 2000 até 2014. Qualquer publicação localizada que não respondesse a tais critérios seria desconsiderada na pesquisa. Foram palavras-chave utilizadas na busca: educação, aprendizagem e projetos de tecnologias de informação e comunicação. Todas consideradas nos Descritores em Ciências da Saúde (DeCS), sendo os termos cruzados como palavras do título e do resumo, com a utilização dos indicadores booleanos or e and.

O levantamento bibliográfico sobre o tema foi realizado na base de dados Scientific Electronic $L i$ brary On-line (SciELO). O objetivo de utilizar esse banco de dados é permitir a pesquisa mais completa possível sobre o tema escolhido.

A pesquisa seguiu em etapas, consistindo a primeira no levantamento bibliográfico conforme os critérios de inclusão e as palavras-chave já apresentados. A segunda etapa: a seleção de material relevante, depois da leitura dos resumos das produções localizadas pela pesquisa no banco de dados, visando a utilizar aquelas que auxiliassem na resposta à questão norteadora da pesquisa.

A terceira etapa incluiu a leitura integral dos artigos, a análise e o fichamento do material selecionado. Por último foi realizada a construção do texto, a partir da reflexão e diálogo com os autores.

\section{Análise de Dados}

Realizado o levantamento bibliográfico na base de dados SciELO, segundo os critérios já aqui especificados, localizou-se um total de sete artigos sobre o tema, tendo sido lidos todos os resumos. Finalizada a avaliação com base nos resumos, foram selecionados cinco artigos para a leitura do conteúdo na íntegra; desse total, todos foram escolhidos para análise e discussão, por estarem de acordo com a proposta do estudo que segue, conforme o Fluxograma 01.

Os cinco artigos selecionados, após leitura na íntegra, foram incorporados e fichados no Quadro 1: Caracterização dos Artigos Constituintes da Amostra, no qual ficam indicados: autores, ano e revista de publicação, objetivos e resultados do estudo. Tal quadro serviu como instrumento norteador para a confecção da análise dos resultados encontrados no presente trabalho, recolhendo-se o que foi considerado em cada artigo, a fim de responder à pergunta central: Como os professores podem utilizar as TICs e as Teorias de Aprendizagem para melhorar o rendimento do aluno dentro da sala de aula?

Após a leitura na íntegra dos cinco artigos selecionados, foi possível identificar pontos de convergência e de divergência sobre o uso de Tecnologias de Informação e Comunicação no processo de aprendizagem dos alunos. Esses pontos serão utilizados como norteadores na discussão que segue. 


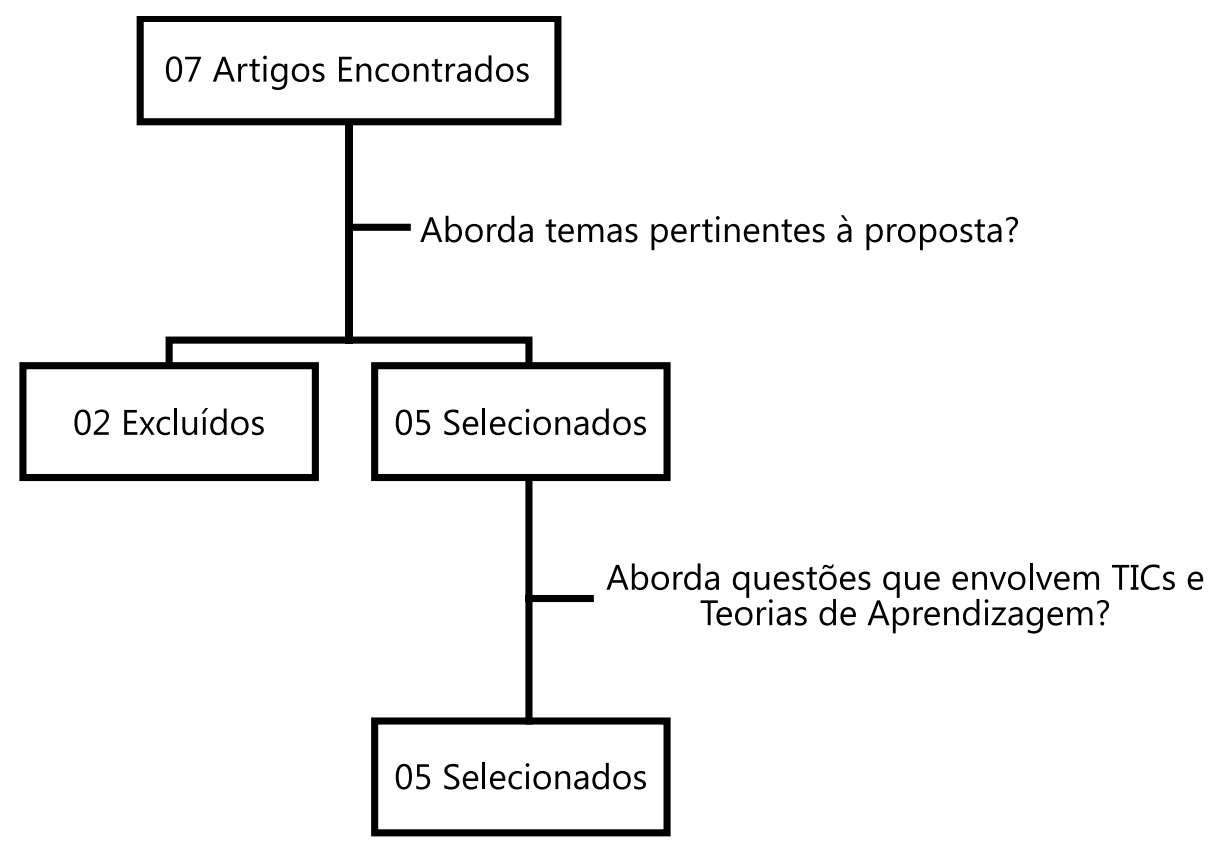

Fluxograma 1 - Critérios de exclusão e inclusão

\begin{tabular}{|c|c|c|c|c|}
\hline Autores/ Ano & Título & Revista & Objetivos & Resultados \\
\hline $\begin{array}{c}\text { ASSMANN, H./ } \\
2000\end{array}$ & $\begin{array}{l}\text { A Metamorfose do } \\
\text { Aprender na Socieda- } \\
\text { de da Informação. }\end{array}$ & $\begin{array}{c}\text { Revista Ciência } \\
\text { da Informação }\end{array}$ & $\begin{array}{c}\text { - Identificar os } \\
\text { aspectos da intensa } \\
\text { transformação dos } \\
\text { modos de aprender } \\
\text { na era das redes. }\end{array}$ & $\begin{array}{c}\text { - As tecnologias de } \\
\text { informação podem } \\
\text { ocasionar melhor entro- } \\
\text { samento no ambiente de } \\
\text { aprendizagem. } \\
\text { - As TICs são importan- } \\
\text { tes, sobretudo no ensino } \\
\text { de tecnologias refinadas, } \\
\text { tais como Inteligência } \\
\text { Artificial. }\end{array}$ \\
\hline $\begin{array}{l}\text { LAGUARDIA, J; } \\
\text { PORTELA, M. } \\
\text { G. \& VASCON- } \\
\text { CELLOS, M. } \\
\text { M./ } 2007\end{array}$ & $\begin{array}{c}\text { Avaliação em Am- } \\
\text { bientes Virtuais de } \\
\text { Aprendizagem. }\end{array}$ & $\begin{array}{c}\text { Educação e } \\
\text { Pesquisa }\end{array}$ & $\begin{array}{c}\text { - Avaliação de Tecno- } \\
\text { logias de Informação } \\
\text { e de Aprendizagem } \\
\text { em EaD. }\end{array}$ & $\begin{array}{c}\text { - Educação e } \\
\text { comunicação } \\
\text { viabilizadas por meio } \\
\text { das TICs: permitem ao } \\
\text { aluno melhor condição } \\
\text { de aprendizagem. }\end{array}$ \\
\hline $\begin{array}{c}\text { CASTILLO, S./ } \\
2008\end{array}$ & $\begin{array}{l}\text { Propuesta Pedagógica } \\
\text { Basada em el Cons- } \\
\text { tructivismo para el } \\
\text { Uso de las TIC em } \\
\text { Constructivismo para } \\
\text { el Uso Óptimo de las } \\
\text { TIC em la Ensenanza } \\
\text { y el Aprendizaje de la } \\
\text { Matemática. }\end{array}$ & $\begin{array}{l}\text { Revista Lati- } \\
\text { no-Americana } \\
\text { de Investigación } \\
\text { en Matemática } \\
\text { Educativa }\end{array}$ & $\begin{array}{l}\text { - Identificar as impli- } \\
\text { cações do construti- } \\
\text { vismo na Educação } \\
\text { Matemática. } \\
\text { - Como os docentes } \\
\text { articulam a prática } \\
\text { pedagógica e o ensino } \\
\text { de matemática com } \\
\text { as TICs. }\end{array}$ & $\begin{array}{c}\text { - O artigo permitiu a } \\
\text { sustentação da proposta } \\
\text { de que o uso das TICs } \\
\text { como suporte para a } \\
\text { aprendizagem, a longo } \\
\text { prazo, transforma o } \\
\text { ambiente em um local } \\
\text { benéfico para a apren- } \\
\text { dizagem através de } \\
\text { projetos. }\end{array}$ \\
\hline
\end{tabular}




\begin{tabular}{|c|c|c|c|c|}
\hline $\begin{array}{c}\text { OBARA, A. T. et } \\
a l . / 2009\end{array}$ & $\begin{array}{l}\text { Environmental } \\
\text { Education in the } \\
\text { Upper Paraná } \\
\text { River Floodplain, } \\
\text { Municipality of Porto } \\
\text { Rico (Paraná State). }\end{array}$ & $\begin{array}{c}\text { Brazilian fournal } \\
\text { of Biology }\end{array}$ & $\begin{array}{c}\text { - Desenvolver e } \\
\text { analisar os seguintes } \\
\text { projetos: Programa } \\
\text { de Educação } \\
\text { Continuada em } \\
\text { Educação Ambiental; } \\
\text { Desenvolvimento } \\
\text { de Projetos } \\
\text { Interdisciplinares; } \\
\text { Inserção de } \\
\text { Tecnologias de } \\
\text { Informação e } \\
\text { Comunicação (TICs) } \\
\text { e Produção de } \\
\text { Material Didático. }\end{array}$ & $\begin{array}{l}\text { - Os professores têm } \\
\text { construído uma base } \\
\text { teórica e metodológica } \\
\text { para educação } \\
\text { ambiental. } \\
\text { - Os professores têm } \\
\text { desenvolvido uma } \\
\text { postura de professor- } \\
\text { pesquisador, ao } \\
\text { criarem condições de } \\
\text { investigação de sua } \\
\text { prática pedagógica, } \\
\text { através de reflexão, de } \\
\text { troca de experiências, } \\
\text { de inovação e de tornar } \\
\text { o processo de ensino- } \\
\text { aprendizagem mais } \\
\text { significativo ao aluno. }\end{array}$ \\
\hline $\begin{array}{l}\text { ARANGO, D. E. } \\
\text { S.; JIMENEZ, F. } \\
\text { Y. M. \& CARO, } \\
\text { E. O./ } 2012 .\end{array}$ & $\begin{array}{c}\text { Convergencia Digital } \\
\text { em la Universidad } \\
\text { Colombiana. Del } \\
\text { Siglo XX al XXI. }\end{array}$ & $\begin{array}{c}\text { Revista de } \\
\text { História da } \\
\text { Educação Latino- } \\
\text { Americana }\end{array}$ & $\begin{array}{l}\text { - Identificar, no } \\
\text { contexto universitá- } \\
\text { rio colombiano, os } \\
\text { desafios de integrar } \\
\text { as tecnologias na } \\
\text { educação. }\end{array}$ & $\begin{array}{l}\text { - As tecnologias digitais } \\
\text { ocasionam variações na } \\
\text { cultura dos sujeitos, o } \\
\text { que implica um estímulo } \\
\text { para voltar a aprender. } \\
\text { - A convergência entre } \\
\text { o mundo digital e o pro- } \\
\text { cesso de aprendizagem } \\
\text { pode beneficiar as insti- } \\
\text { tuições universitárias. }\end{array}$ \\
\hline
\end{tabular}

Quadro 1 - Caracterização dos artigos constituintes da amostra.

Todos os artigos apontaram o uso das Tecnologias de Informação e Comunicação como um fator positivo que deve ser estimulado e explorado cada vez mais, para que se consolide no ambiente escolar. No entanto, o modo como tal recurso será incluído irá diferir, de maneira a respeitar a demanda e as possibilidades dos locais.

Dois artigos evidenciaram que a postura do docente frente às tecnologias é fator determinante no processo de aprendizagem, indicando que o receio de aceitar novos recursos no ambiente de sala de aula decorre da ausência de experiências anteriores para se espelhar e lidar com tal situação e que, quanto mais o professor pesquisa e se aprimora, mais significativo é o processo de ensino-aprendizagem
(OBARA et al., 2009; ARANGO, JIMENEZ \& CARO, 2012).

Apesar de enfocar o ensino da matemática, outro artigo destaca também o uso das TICs como ferramentas para que o aluno consiga desenvolver seu conhecimento através de um processo de reflexão, em que o professor, com auxílio de tecnologias, inicia um caminho de consolidação do conhecimento prévio em conjunto com o conhecimento científico recém-adquirido (CASTILLO, 2008).

$\mathrm{O}$ artigo mais antigo localizado faz uma reflexão acerca de como devem ser vistas as novas possibilidades, trazendo o conceito de Pierre Lévy sobre a denominada Inteligência Coletiva, que evidencia que o conhecimento não é mais unilateral, 
mas criado através da cooperação entre as partes envolvidas no processo (ASSMANN, 2000).

Um dos artigos encontrados tem um enfoque mais específico sobre o ensino a distância, o qual somente pode ser oferecido devido aos avanços das Tecnologias de Informação e Comunicação. Nesse artigo há uma preocupação em explicitar o quão proveitoso pode ser o recurso audiovisual no aprendizado do aluno, tanto da criança como do adulto (LAGUARDIA, PORTELA \& VASCONGELLOS, 2007).

Como podemos perceber, por mais que os artigos abordem o mesmo tema das mais diversas maneiras, todos carregam pontos em comum com a aprendizagem significativa e com a prática do Professor Reflexivo, algo extremamente positivo, pois demonstra que é possível associar as TICs com as boas práticas pedagógicas do docente, seja no ensino fundamental, médio ou superior.

\section{Considerações Finais}

Os trabalhos indicam que os docentes podem utilizar as TICs em conjunto com as tecnologias de aprendizagem de diversas maneiras para auxiliar no rendimento do aluno em seu processo de aprendizagem, tais como: usar recursos audiovisuais, incitar a pesquisa em sala de aula, estimular a articulação entre o que foi discutido em sala e o que aparece na internet, ou ainda incentivar que os alunos complementem entre si o que foi discutido.

O professor, ao se perceber como articulador e não mais como o grande detentor de conhecimento, tal como era antes com o modelo tradicional de educação, conseguirá pensar e incorporar as possibilidades que as TICs proporcionam, beneficiando tanto o docente como os alunos.

\section{Referências Bibliográficas}

ALARCÃO, I. Professores Reflexivos em uma Escola Reflexiva. 4. ed. São Paulo: Cortez, 2005
ALMEIDA, M. E. B. O Computador na Escola: Contextualizando a Formação de Professores. Tese (doutorado em Educação: Currículo), Pontifícia Universidade Católica de São Paulo, 2000.

ANASTASIOU, L. G. C. \& PESSATE, L. A. Processos de Ensinagem na Universidade: Estratégias de Trabalho em Aula. Joinville: Editora Univille, 2007.

ARANGO, D. E. S.; JIMENEZ, F. Y. M. \& CARO, E. O. "Convergencia Digital em la Universidad Colombiana. Del siglo XX al XXI". Rev. Hist. Educ. Latinoam. Tunja, vol. 14, n. 19, dez. 2012.

ASSMANN, H. "A Metamorfose do Aprender na Sociedade da Informação". Ci. Inf., Brasília, vol. 29, n. 2, ago. 2000.

AUSUBEL, D. P. A Aprendizagem Significativa: A Teoria de David Ausubel. São Paulo: Moraes, 1982.

AVANCINI, M; CONTE, F \& GOUVEIA, F. "Entrevista com Pierre Lévy". Com Ciência, Campinas, n. 131, 2011.

BRASIL. "Apresentação ProInfo". FNDE - Fundo Nacional de Desenvolvimento da Educaşão. Brasília, 2012.

CASTILlO, S. "Propuesta Pedagógica Basada en el Constructivismo para el Uso Óptimo de las TIC en la Enseñanza y el Aprendizaje de la Matemática". Relime, México, vol. 11, n. 2, jun. 2008.

CAVALCANTI, R. A. "Andragogia: A Aprendizagem nos Adultos". Revista de Clínica Cirúrgica da Paraíba, n. 6, ano 4, jul. 1999.

LAGUARDIA, J.; PORTELA, M. C. \& VASCONCELLOS, M. M. "Avaliação em Ambientes Virtuais de Aprendizagem”. Educ. Pesqui., São Paulo, vol. 33, n. 3, dez. 2007.

MOREIRA, Marco A. Aprendizagem Significativa: a Teoria de David Ausubel. São Paulo: Moraes, 1982.

OBARA, A. T. et al. "Environmental Education in the Upper Paraná River Floodplain, Municipality of Porto Rico (Paraná State), Brazil". Braz. F. Biol., São Carlos, vol. 69, n. 2, supl. jun. 2009.

ROSSETTI, A. G. \& MORALES, A. B. T. "O Papel da Tecnologia da Informação na Gestão do Conhecimento". Ci. Inf., Brasília, vol. 36, n. 1, pp. 124-135, jan./abr. 2007.

VASCONCELLOS, C. dos S. "Metodologia Dialética em Sala de Aula". Revista de Educaşão AEC, Brasília, n. 83, abr. 1992. 